\title{
A dimensionless analysis of heat and mass transport in an adsorber with thin fins; uniform pressure approach ${ }^{\hbar}$
}

\author{
Gamze Gediz Ilis ${ }^{\text {a }}$, Moghtada Mobedi ${ }^{\text {a,* }}$, Semra Ülkü ${ }^{b}$ \\ a Mechanical Engineering Department, Izmir Institute of Technology, Urla 35430, Izmir, Turkey \\ b Chemical Engineering Department, Izmir Institute of Technology, Urla 35430, Izmir, Turkey
}

\section{A R T I C L E I N F O}

Available online 22 March 2011

Keywords:

Adsorption

Heat and mass transfer

Adsorbent bed

Fin

\begin{abstract}
A B S T R A C T
A numerical study on heat and mass transfer in an annular adsorbent bed assisted with radial fins for an isobaric adsorption process is performed. A uniform pressure approach is employed to determine the changes of temperature and adsorbate concentration profiles in the adsorbent bed. The governing equations which are heat transfer equation for the adsorbent bed, mass balance equation for the adsorbent particle, and conduction heat transfer equation for the thin fin are non-dimensionalized in order to reduce number of governing parameters. The number of governing parameters is reduced to four as Kutateladze number, thermal diffusivity ratio, dimensionless fin coefficient and dimensionless parameter of $\Gamma$ which compares mass diffusion in the adsorbent particle to heat transfer through the adsorbent bed. Temperature and adsorbate concentration contours are plotted for different values of defined dimensionless parameters to discuss heat and mass transfer rate in the bed. The average dimensionless temperature and average adsorbate concentration throughout the adsorption process are also presented to compare heat and mass transfer rate of different cases. The values of dimensionless fin coefficient, $\Gamma$ number and thermal diffusivity ratio are changed from 0.01 to 100,1 to $10^{-5}$ and 0.01 to 100 , respectively; while the values of Kutateladze number are 1 and 100. The obtained results revealed that heat transfer rate in an adsorbent bed can be enhanced by the fin when the values of thermal diffusivity ratio and fin coefficient are low (i.e., $\alpha^{*}=0.01, \Lambda=0.01$ ). Furthermore, the use of fin in an adsorbent bed with low values of $\Gamma$ number (i.e. $\Gamma=10^{-5}$ ) does not increase heat transfer rate, significantly.
\end{abstract}

(C) 2011 Elsevier Ltd. All rights reserved.

\section{Introduction}

Adsorption phenomena have broad range of applications in nature as well as in industry. It plays an important role in the catalytic reaction and separation/purification processes such as recovery of the chemical compounds, water purification, separation, and purification of air, drying, medical treatments, and recently thermally driven energy systems. The period and capacity of an adsorption process are two significant criteria that should be considered in design of an adsorption system. For instance, a high adsorption capacity in a short adsorption period is required in order to have high specific cooling or heating performance for an adsorption heat pump [1]. The adsorption rate in an adsorbent particle or an adsorbent layer is highly influenced from its temperature. Determinations of adsorption capacity and adsorption period of a process are not easy, since heat and mass transports are highly coupled. The solution of heat and mass transport

\footnotetext{
th Communicated by W.J. Minkowycz.

* Corresponding author.

E-mail address: moghtadamobedi@iyte.edu.tr (M. Mobedi).
}

equations for an adsorption process provides useful information that can be used for an adsorbent bed design.

Literature survey showed that theoretical and experimental studies were performed on heat and mass transfer in the adsorbent beds as well as in the desiccant wheels. Golubovic and Worek [2] studied the pressure effect on sorption process in rotary desiccant wheels. They used an implicit finite-difference scheme to detect condensation in regeneration portion of a desiccant wheel operating at high pressures. Al-Sharqawi and Lior [3] performed a conjugate computation study on heat and fluid flow in channels and over silica gel desiccant plates for laminar and turbulent flows of humid air. The results of their study showed that the heat and mass transfer coefficients decrease with increase of desiccant plate thickness. Sphaier and Worek [4] proposed a novel solution scheme for a periodic heat and mass transfer in a regenerator. The method consists of a combination of the finite-volume method and the numerical method of lines. Ruivo et al. [5] discussed the importance of surface diffusion which is the most important mechanism of water transport within the silica gel for desiccant wheels.

Studies on heat and mass transfer in closed adsorbers such as adsorbent bed of adsorption heat pumps were also reported in 


\author{
Nomenclature \\ $\mathrm{C}_{\mathrm{p}} \quad$ specific heat, $\mathrm{J} / \mathrm{Kg} \mathrm{K}$ \\ D diffusivity, $\mathrm{m}^{2} / \mathrm{s}$ \\ k thermal conductivity, $\mathrm{W} / \mathrm{mK}$ \\ $\mathrm{Ku} \quad$ Kutateladze number \\ $\mathrm{P} \quad$ pressure, $\mathrm{Pa}$ \\ $r_{p} \quad$ radius of adsorbent particle, $m$ \\ $\mathrm{R} \quad$ radial direction, $\mathrm{m}$ \\ $\mathrm{T}$ temperature, $\mathrm{K}$ \\ $\mathrm{t}$ time, $\mathrm{s}$ \\ W local adsorbate concentration, $\mathrm{kg}_{l} / \mathrm{kg}_{s}$ \\ Greek symbols \\ $\alpha \quad$ thermal diffusivity, $\mathrm{m}^{2} / \mathrm{s}$ \\ $\Phi \quad$ porosity \\ $\phi \quad$ angular direction \\ $\delta \quad$ half of fin thickness, $m$ \\ $\Gamma \quad$ a dimensionless parameter \\ $\Lambda \quad$ dimensionless fin coefficient \\ $\rho \quad$ density, $\mathrm{kg} / \mathrm{m}^{3}$ \\ $\Delta H_{\text {ads }} \quad$ heat of adsorption, $\mathrm{J} / \mathrm{kg}_{\mathrm{v}}$ \\ $\theta \quad$ dimensionless temperature \\ $\tau$ dimensionless time

\section{Subscripts} \\ d, a initial and final conditions (Fig. 2) \\ i inner \\ eff effective \\ fs fin surface \\ $l, s, v \quad$ adsorbate, adsorbent, adsorptive \\ sat saturation \\ o outer \\ $\infty \quad$ equilibrium

\section{Superscripts} \\ * dimensionless quantity \\ - $\quad$ average
}

literature. Demir et al. [6] studied porosity effects on heat and mass transfer in a granular adsorbent bed during an adsorption process. The heat and mass transfer equations for an annular adsorbent bed were solved numerically. Ilis et al. [7] performed a numerical study in an adsorbent bed during an isobaric adsorption process. They defined two dimensionless parameters which control heat and mass transfer in a granular adsorbent bed. Leong and Liu [8] numerically studied heat and mass recovery adsorption cooling cycle to investigate effects of system design and operation parameters on performance of adsorption heat pump cycle. Heat and mass transfer equations for adsorbent bed and mass transfer equation for adsorbent particle are non-dimensionalized in their study. Other theoretical studies on heat and mass transfer in a closed adsorption system can also be found in literature [9-12].

Heat and mass transfer rate in an adsorbent bed of a closed adsorption system depends on many parameters such as particle size, thermal conductivity, thermal diffusivity, adsorption equilibria, mass diffusivity, and porosity. Theoretical or experimental study to discover the effect of each parameter on heat and mass transfer in an adsorbent bed is difficult since the number of governing parameters is too much. The non-dimensionalization of problem can reduce number of governing parameters and simplify the understanding of their effects on adsorption or desorption process. The aim of present study is to perform a dimensionless analysis on heat and mass transfer through an annular adsorbent bed assisted with radial fins during an isobaric adsorption process. The non-dimensionalization of heat transfer equation for the adsorbent bed and mass balance equation for the adsorbent particle yields two dimensionless parameters as Kutateladze number and a dimensionless parameter denoted by $\Gamma$ which compares the rates of mass diffusion within the adsorbent particle and heat diffusion in the adsorbent bed. Moreover, the nondimensionalization of conduction heat transfer equation of radial fin yields two dimensionless parameters as dimensionless fin coefficient parameter and thermal diffusivity ratio. The solution of the governing equations under assumed initial and boundary conditions is obtained and the results are presented via temperature and adsorbate concentration contours. Based on our knowledge, no dimensionless study on heat and mass transfer in an adsorbent bed with fins for an isobaric adsorption process has been conducted.

\section{The considered adsorbent bed}

The analyzed adsorbent bed is an annular bed with inner fins in radial direction as shown in Fig. 1. The silica gel-water pair is working pair and the silica gel particles located between fins. It is assumed that the upper and lower surfaces of bed are well insulated and the adsorbent bed is enough long, so the end effects can be neglected. The heat and mass are transferred only in radial and angular directions of the bed. Initially, the adsorbent bed is at $T_{d}$ temperature and adsorbate concentration in the bed is $W_{\mathrm{d}}$ as shown in Fig. 2(a). Suddenly, the temperature of the bed outer surface falls to $T_{a}$ and the valve between the adsorbent bed and the evaporator ( $\mathrm{V} 1$ valve) is opened to allow the transfer of adsorptive (i.e., water vapor) to the bed. The adsorptive can flow easily between the silica gel particles. The interparticle mass transfer resistance is neglected. The process is isobaric and the bed pressure is not changed during the adsorption process. The bed final temperature is $T_{a}$ and the corresponding adsorbate concentration is $W_{\mathrm{a}}$. The inner and outer radiuses of the adsorbent bed are 50 and $110 \mathrm{~mm}$, respectively. Number of fins in the adsorbent bed is 12 . A schematic view of dimensionless adsorption equilibria is shown in Fig. 2(b).

\section{Governing equations}

The mechanism of heat and mass transfer in a granular adsorbent bed is complex and the governing equations are coupled, so some assumptions are required. The assumptions made in this study are; 1) the adsorbent bed consists of uniform size adsorbent particle, 2) adsorptive and adsorbent particles are in thermodynamic equilibrium, 3) the internal and external thermal resistances are neglected for the adsorbent particle, 4) thermal properties of the adsorbent, adsorptive and adsorbate are constant, and 5) the wall thermal

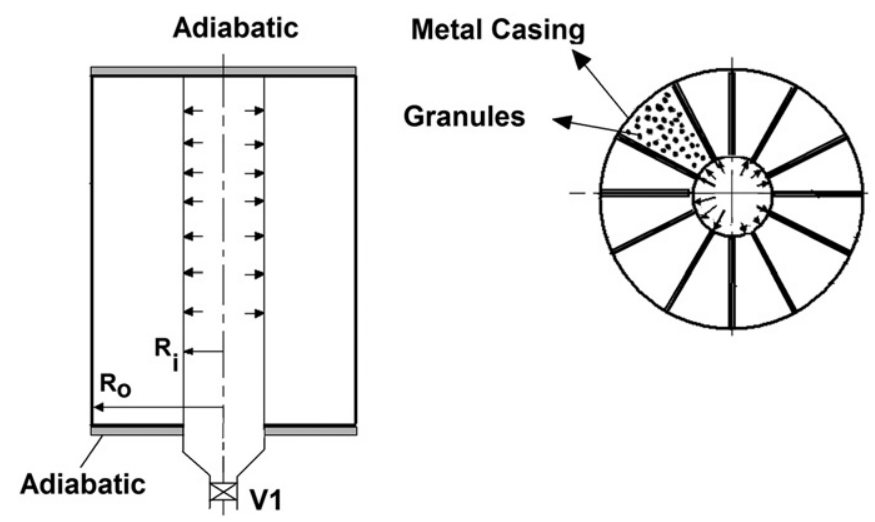

Fig. 1. The front and top views of the analyzed adsorbent bed with 12 fins inside. 


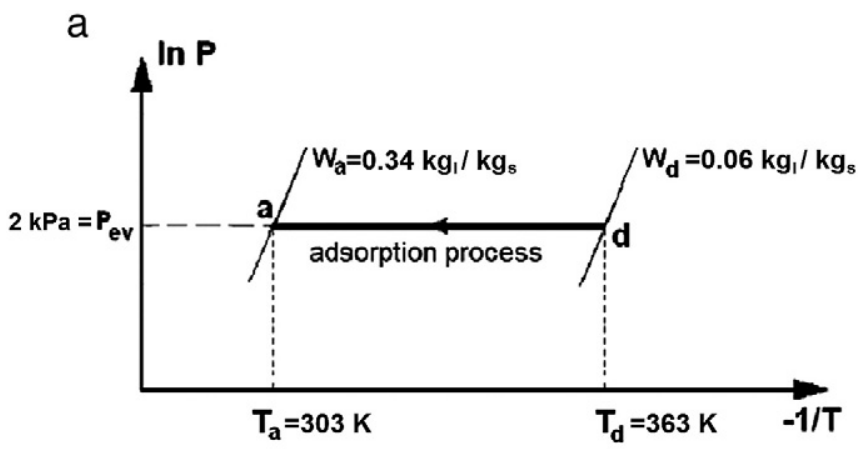

b

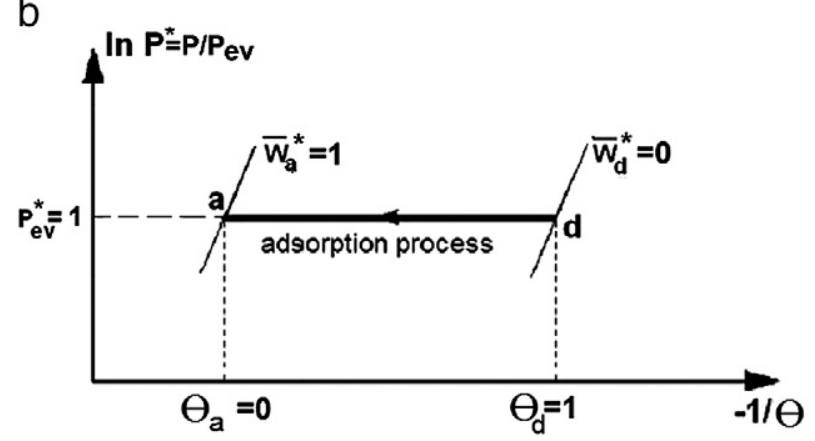

Fig. 2. A schematic view of adsorption process on Clapeyron diagram, (a) dimensional isoster, and (b) dimensionless isoster.

resistance between the bed surface and adsorbent particle is not considered. Under the above mentioned assumptions, the heat transfer equation for the adsorbent bed can be written as:

$\frac{\partial \mathrm{T}}{\partial \mathrm{t}}=\alpha_{\text {eff }} \frac{1}{\mathrm{R}} \frac{\partial}{\partial \mathrm{R}}\left(\mathrm{R} \frac{\partial \mathrm{T}}{\partial \mathrm{R}}\right)+\frac{1}{\mathrm{R}^{2}} \frac{\partial^{2} \mathrm{~T}}{\partial \phi^{2}}+\frac{(1-\varphi) \rho_{s}}{\left(\rho C_{\mathrm{p}}\right)_{\mathrm{eff}}} \Delta H_{a d s} \frac{\partial W}{\partial \mathrm{t}}$

where $\alpha_{\text {eff }}$ is the effective thermal diffusivity. An equation for determination of adsorption rate in the adsorbent particle is required. In this study, the LDF method is used to determine the adsorption rate in the adsorbent particle [7].

$\frac{\partial W}{\partial \mathrm{t}}=\frac{15 \mathrm{D}_{\mathrm{eff}}}{\mathrm{r}_{\mathrm{p}}^{2}}\left(W_{\infty}-W\right)$

Uniform temperature distribution can be assumed in the cross section of the thin fin, (i.e., $T_{\text {fin }}=f(R, t)$ ). The conduction heat transfer equation for the thin fin can be written as:

$\left(\rho \mathrm{C}_{\mathrm{p}}\right)_{\mathrm{fin}} \delta \frac{\partial \mathrm{T}_{\mathrm{fin}}}{\partial \mathrm{t}}=\left.\mathrm{k}_{\mathrm{s}} \frac{1}{\mathrm{R}} \frac{\partial \mathrm{T}_{\mathrm{fin}}}{\partial \phi}\right|_{\mathrm{fs}}+k_{\mathrm{fin}} \frac{\partial^{2} \mathrm{~T}_{\mathrm{fin}}}{\partial \mathrm{R}^{2}} \delta$.

The second term of Eq. (3) represents the rate of heat enters or leaves the bed lateral surfaces. Eqs. (1), (2), and (3) can be nondimensionalized by using the following dimensionless parameters:

$$
W^{*}=\frac{W-W_{\mathrm{d}}}{W_{\mathrm{a}}-W_{\mathrm{d}}} ; \theta=\frac{\mathrm{T}-\mathrm{T}_{\mathrm{a}}}{\mathrm{T}_{\mathrm{d}}-\mathrm{T}_{\mathrm{a}}} ; \mathrm{R}^{*}=\frac{\mathrm{R}}{\mathrm{R}_{\mathrm{i}}} ; \tau=\frac{\alpha_{\mathrm{eff}} \mathrm{t}}{\mathrm{R}_{\mathrm{i}}^{2}} .
$$

By using the above dimensionless parameters, the dimensionless forms of the bed heat transfer equation, particle mass balance equation and fin heat conduction equation become as:

$\frac{\partial \theta}{\partial \mathrm{t}}=\frac{1}{\mathrm{R}^{*}} \frac{\partial}{\partial \mathrm{R}^{*}}\left(\mathrm{R}^{*} \frac{\partial \theta}{\partial \mathrm{R}^{*}}\right)+\frac{1}{\mathrm{R}^{* 2}} \frac{\partial^{2} \theta}{\partial \phi^{2}}+\mathrm{Ku} \frac{\partial \bar{W}^{*}}{\partial \mathrm{t}}$ $\frac{\partial W^{*}}{\partial \mathrm{t}}=15 \Gamma\left(W_{\infty}^{*}-W^{*}\right)$

$\alpha^{*} \frac{\partial \theta_{\text {fin }}}{\partial \tau}=\left.\Lambda \frac{1}{\mathrm{R}^{*}} \frac{\partial \theta}{\partial \phi}\right|_{\mathrm{fs}}+\frac{\partial^{2} \theta_{\mathrm{fin}}}{\partial \mathrm{R}^{* 2}}$

where dimensionless parameters of $\mathrm{Ku}, \Gamma, \Lambda$, and $\alpha^{*}$ are:

$\mathrm{Ku}=\frac{\rho_{s} \Delta H_{a d s}(1-\varphi) \Delta W}{\left(\rho C_{\mathrm{p}}\right)_{\mathrm{eff}} \Delta \mathrm{T}} ; \Gamma=\frac{\mathrm{D}_{\mathrm{eff}} / \mathrm{r}_{\mathrm{p}}^{2}}{\alpha_{\mathrm{eff}} / \mathrm{R}_{i}^{2}} ; \Lambda=\frac{\mathrm{k}_{\mathrm{eff}}}{\mathrm{k}_{\mathrm{fin}}} \frac{\mathrm{R}_{\mathrm{i}}}{\delta} ; \alpha^{*}=\frac{\alpha_{\mathrm{eff}}}{\alpha_{\mathrm{fin}}}$.

$\mathrm{Ku}$ represents Kutateladze number which is a dimensionless parameter that shows the ratio of the generated heat due to adsorption and the sensible stored heat in adsorbent bed [13]. The dimensionless $\Gamma$ parameter compares the adsorbate diffusion in the adsorbent particle to the transport of heat transfer throughout the adsorbent bed. The dimensionless parameter of $\Lambda$ is the dimensionless fin coefficient and refers to the ratio of heat transfer from the fin lateral surface to the diffusion of heat in radial direction of the fin. Finally, $\alpha^{*}$ parameter is the ratio of effective thermal diffusivities of adsorbent medium and fin. The following isotherm equation is used to determine the equilibrium adsorbate concentration in the silica gel for a given pressure and temperature [6]:

$W_{\infty}=\mathrm{m}\left(\mathrm{P} / \mathrm{P}_{\text {sat }}\right)^{1 / \mathrm{n}}$.

The values of $\mathrm{m}$ and $\mathrm{n}$ are 0.552 and 1.6 , respectively in this study for the considered silica gel-water pair. Since the dimensionless forms of the governing equations are solved, the dimensionless adsorption equilibrium relation is required. By using dimensionless parameter groups represented by Eq. (4), an equation which yields the variation of $W_{\infty}^{*}$ in terms of $\theta$ can be obtained:

$W_{\infty}^{*}=-0.774 \theta^{3}+2.13 \theta^{2}-2.355 \theta+0.995$.

The above equation is valid for an adsorption process under a bed pressure of $\mathrm{P}=2 \mathrm{kPa}$ and the operation temperature ranges from 303 to $363 \mathrm{~K}$ (i.e., $\mathrm{T}_{\mathrm{a}}=303 \mathrm{~K}$ and $\mathrm{T}_{\mathrm{d}}=363 \mathrm{~K}$ ). The initial and boundary conditions for Eqs. (5), (6) and (7) can be written as:

$\tau=0 ; \quad \theta=1 ; W^{*}=0$

$\mathrm{R}^{*}=1 ; \quad \partial \theta / \partial \mathrm{R}^{*}=0$

$\mathrm{R}^{*}=\mathrm{R}_{\mathrm{o}} / \mathrm{R}_{\mathrm{i}} ; \quad \theta=0$

$\phi=0 ; \quad \theta=\theta_{\text {fin }}$

$\phi=\phi_{0} ; \quad \partial \theta / \partial \mathrm{R}^{*}=0$

The initial and boundary conditions for Eq. (7) are

$\tau=0 ; \quad \theta_{\text {fin }}=1$

$\mathrm{R}^{*}=1 ; \quad \partial \theta_{\mathrm{fin}} / \partial \mathrm{R}^{*}=0$

$\mathrm{R}^{*}=\mathrm{R}_{\mathrm{o}} / \mathrm{R}_{\mathrm{i}} ; \quad \theta_{\text {fin }}=0$.

\section{Solution method}

Finite difference method is used to solve the governing equations. By substituting of initial values, heat transfer equation for the bed, (Eq. (5)) is solved to determine the local dimensionless temperature in the adsorbent bed. Then, by using the dimensionless temperature 
values, mass transfer equation for adsorbent particle (Eq. (6)) is solved to calculate the distribution of the dimensionless adsorbate concentration in the bed. Then, the conduction heat transfer equation for the fin, (Eq. (7)) is solved to determine temperature distribution in radial direction of fin. An inner iteration is made to obtain the simultaneous solution of heat transfer equation for the bed, mass balance equation for the adsorbent particle and conduction heat transfer for the fin. The following convergence criterion was used for the convergence of inner iterations;

$\left|\frac{\gamma^{\mathrm{n}+1}-\gamma^{\mathrm{n}}}{\Delta \tau}\right|<10^{-6}$

where $\gamma$ represents $W^{*}$ and $\theta$, and $n$ shows a time step. After converging of the inner iteration, time step is increased and computations continues to determine the distribution of $W^{*}$ and $\theta$ for the next step. The procedure continues until the average adsorbate concentration and average temperature reach to their final values considered as $\bar{W}^{*}=0.99$ and $\theta=0.01$.

\section{Result and discussion}

The distributions of dimensionless temperature and adsorbate concentration in the half of the region between two fins at different steps of adsorption process are shown via contours. Fig. 3 shows the distribution of dimensionless temperature in the half region between two fins at four time steps of adsorption period when $\mathrm{Ku}=1, \Gamma=1$, $\Lambda=100$, and $\alpha^{*}=0.01$. As it was mentioned before, the bed initial temperature is 1 (i.e., $\theta=1$ ) and suddenly the bed outer surface temperature, and consequently the base temperature of fin, drops to $\theta=0$. After $\tau=0.001$, the distribution of dimensionless temperature in the adsorbent bed is shown in Fig. 3(a). The temperature in the region close to the bed outer surface is smaller than the temperature of center region. Temperature gradient in radial direction of thin fin is very similar to the temperature gradient in the region between two fins. It seems that the thin fin does not have considerable effect on heat transfer in the bed since no remarkable temperature gradient is observed in angular direction of the bed. Although the fin thermal diffusivity is greater than bed effective thermal diffusivity, $\alpha_{\mathrm{fin}}>\alpha_{\mathrm{eff}}$, heat flux from lateral surfaces of the thin fin is remarkably greater than the heat flux through the radial direction of the fin due to large value of dimensionless fin coefficient (i.e., $\Lambda=100$ ). Therefore, no temperature gradient in the angular direction in the bed exits and temperatures of fin and the adsorbent region are almost identical. As seen from Fig. 3(b) and (c), the temperature decreases by time in radial direction (i.e., from the outer to inner surface), and the temperature of center region drops to the surface temperature (i.e. $\theta=0$ ) after $\tau=3.77$ (Fig. 3(d)).

The distribution of adsorbate concentration at the four time steps of adsorption process of Fig. 3 is shown in Fig. 4. The dimensionless adsorbate concentration in the adsorbent particles is zero at the beginning of the adsorption process. After opening V1 valve, shown in Fig. 1, the adsorbate vapor uniformly enters to the bed from the inner surface. The adsorption rate in the adsorbent particle depends on equilibrium adsorbate concentration and consequently on the adsorbent particle temperature. As seen from Fig. 4(a) and (b), the adsorption rate in the region with low temperature (i.e., region close to $R=R_{0}$ ) is higher than the concentration in region close to $R=R_{i}$. The particle temperature in the center region decreases over time, and consequently the adsorbate concentration increases (Fig. 4(c)). The gradient of adsorbate concentration in angular direction is negligible due to the small angular gradient of temperature. The dimensionless adsorbate concentration in the bed is 1 at the end of adsorption period. No further adsorption almost occurs in the bed after $\tau=3.77$.
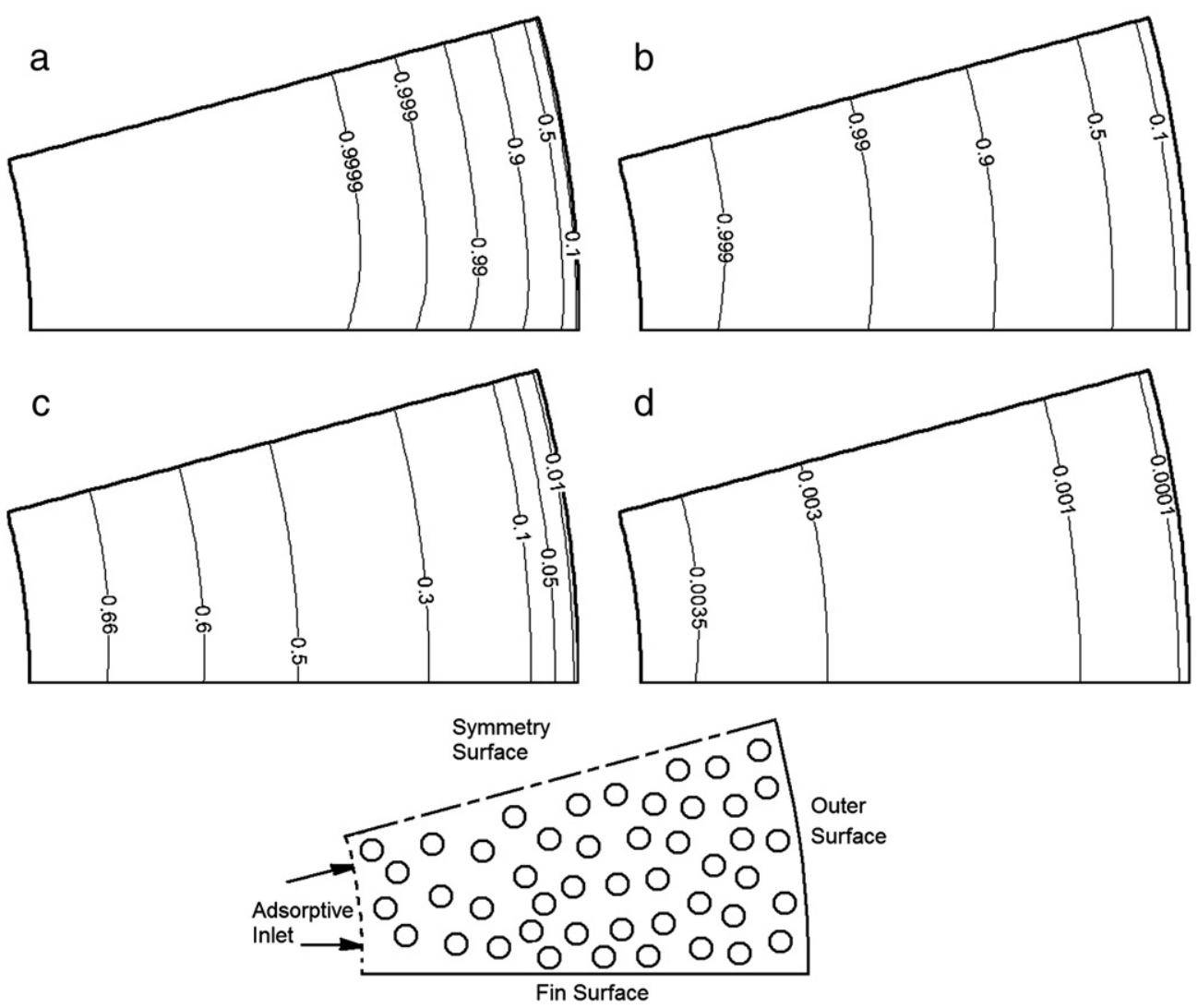

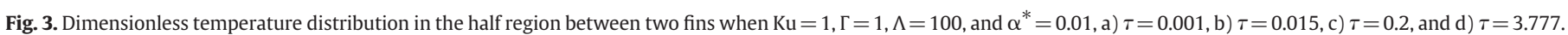


Fig. 5 shows the temperature distribution in the half region between two fins in the adsorbent bed when $\mathrm{Ku}=1, \Gamma=1, \alpha^{*}=0.01$, but $\Lambda=0.01$. The decrease of $\Lambda$ signifies the increase of heat conduction in radial direction of fin. As seen from Fig. 5(a), illustrating the distribution of dimensionless temperature at $\tau=0.001$, fin temperature is lower than bed temperature. The temperature of entire fin is almost equal to the base temperature of fin at $\tau=0.015$ (Fig. 5(b)). The low value of $\Lambda$ (i.e., $\Lambda=0.01$ ) causes a higher conduction heat transfer in radial direction of thin fin, and the fin temperature quickly drops to the base temperature (i.e., $\theta=0$ ). That is why, a remarkable temperature gradient in angular direction is observed. The temperature in the region between two fins drops to the surface temperature (i.e., $\theta=0$ ) after $\tau=0.878$ as seen from Fig. 3(d). The decrease in $\Lambda$ value from 100 to 0.01 reduces the adsorption period by 4.3 -fold.

The temperature distribution in the bed at four time steps of adsorption process when $\mathrm{Ku}=1, \Gamma=1, \Lambda=0.01$, but for an extreme thermal diffusivity ratio as $\alpha^{*}=100$ is shown in Fig. 6 . The temperature distribution in the bed is different than that presented in Fig. 5, for which $\alpha^{*}=0.01$. A high value of $\alpha^{*}$ (i.e., $\alpha^{*}>1$ ) refers to the lower thermal diffusivity of fin compared to the bed effective thermal diffusivity. Therefore, the heat propagation in the bed is faster than the heat diffusion through the radial direction of fin. As clearly seen from Fig. 6, the cooling rate in the region close to the fin is smaller than the cooling rate in the center, and consequently, the bed cannot be cooled via fins for the cases with $\alpha^{*}=100$. The increase of $\alpha^{*}$ value from 0.01 to 100 prolongs the adsorption period by 177 -fold and the total period of adsorption increases from 0.878 to 156.03 .

Fig. 7 depicts the changes in average temperature and adsorbate concentration of the bed during the adsorption process when $\Gamma=1$, $\Lambda=0.01$ and for two Kutateladze numbers of 1 and 100 . The change in average temperature and adsorbate concentration when no fin exists in the adsorbent bed is also plotted in the same figure. As seen from Fig. 7, the average dimensionless temperature decreases while the average adsorbate concentration increases during the adsorption process. The effect of fin on heat and mass transfer rate in the bed can be observed clearly. The duration of adsorption process in an adsorbent bed without fin when $\mathrm{Ku}=1$ and $\Gamma=1$ is $\tau_{\text {total }}=3.86$. The use of 12 fins with $\Lambda=0.01$ and $\alpha^{*}=0.01$ reduces this period to $\tau_{\text {total }}=0.878$. The use of fin reduces the dimensionless adsorption period by $439 \%$. The increase of Ku value from 1 to 100 increases heat generation in the bed, and the adsorption period is increased (Fig. 7(b)). The use of 12 fins with $\Lambda=0.01$ and $\alpha^{*}=0.01$ reduces the adsorption period from 233.5 to 38.8 when $\mathrm{Ku}=100$. The percentage reduction of adsorption period for the adsorbent bed with $\mathrm{Ku}=100$ by using 12 fins is $601 \%$ which is higher than the reduction in the period of bed with $\mathrm{Ku}=1$. This result shows that for the adsorbent beds with high values of Ku number (i.e., $\mathrm{Ku}=100$ ), the role of fin on the reduction of adsorption period becomes more significant.

In order to present the effect of $\Gamma$ number on heat and mass transfer rate in an adsorbent bed, Fig. 8 is presented. In this figure, the changes in average temperature and adsorbate concentration in a bed with $\Gamma=10^{-5}$ for two values of $\mathrm{Ku}=1$ and 100 are illustrated while no fin exists in the adsorbent bed. The variation of average temperature and concentration for $\mathrm{Ku}=1$ and $\mathrm{Ku}=100$ is almost identical and temperature curves overlap. The bed average temperature rapidly falls to $\theta=0$, while the adsorbate concentration increases slowly over time. As it was mentioned before, $\Gamma$ parameter compares the mass diffusion in the radial direction of adsorbent particle to the diffusion of heat in the adsorbent bed. The low value of $\Gamma$ refers to higher heat transfer rate in the adsorbent bed and therefore the bed temperature rapidly falls to the outer surface temperature. Therefore, the mass diffusion in the adsorbent particle controls the
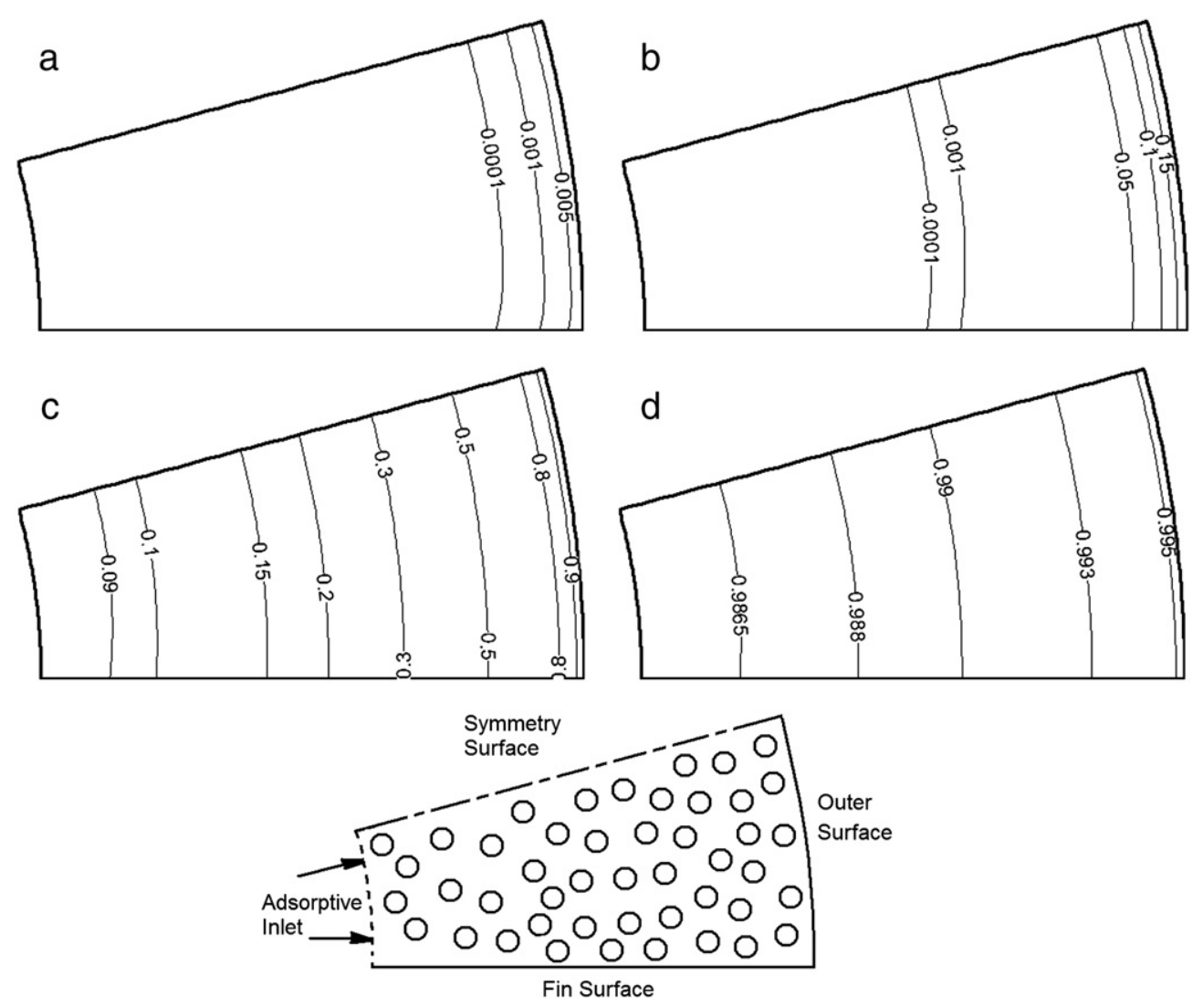

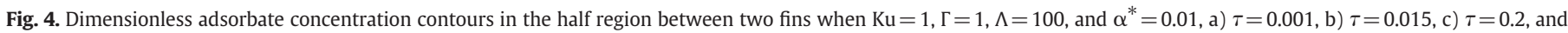
d) $\tau=3.77$. 

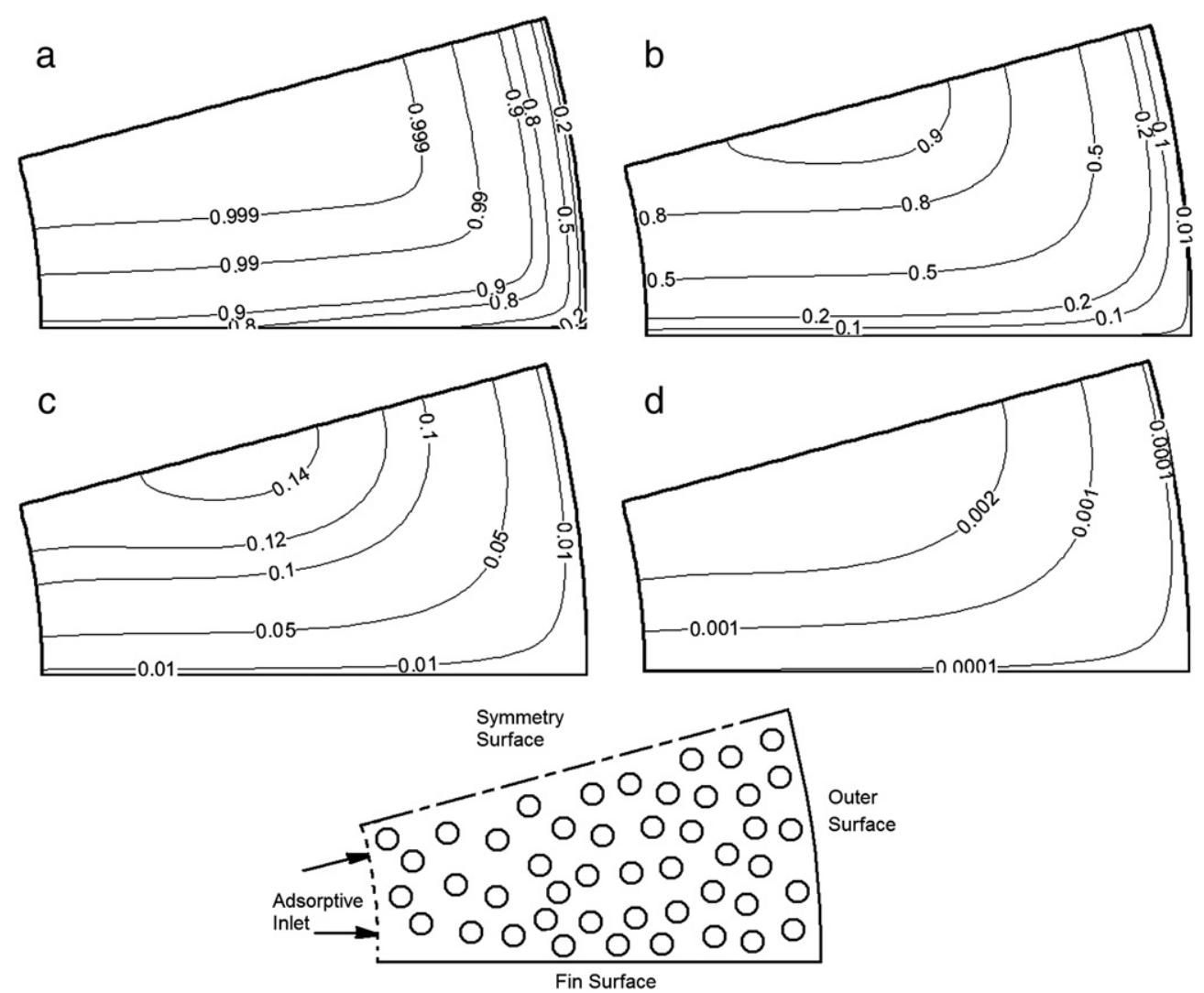

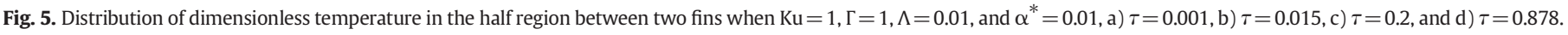
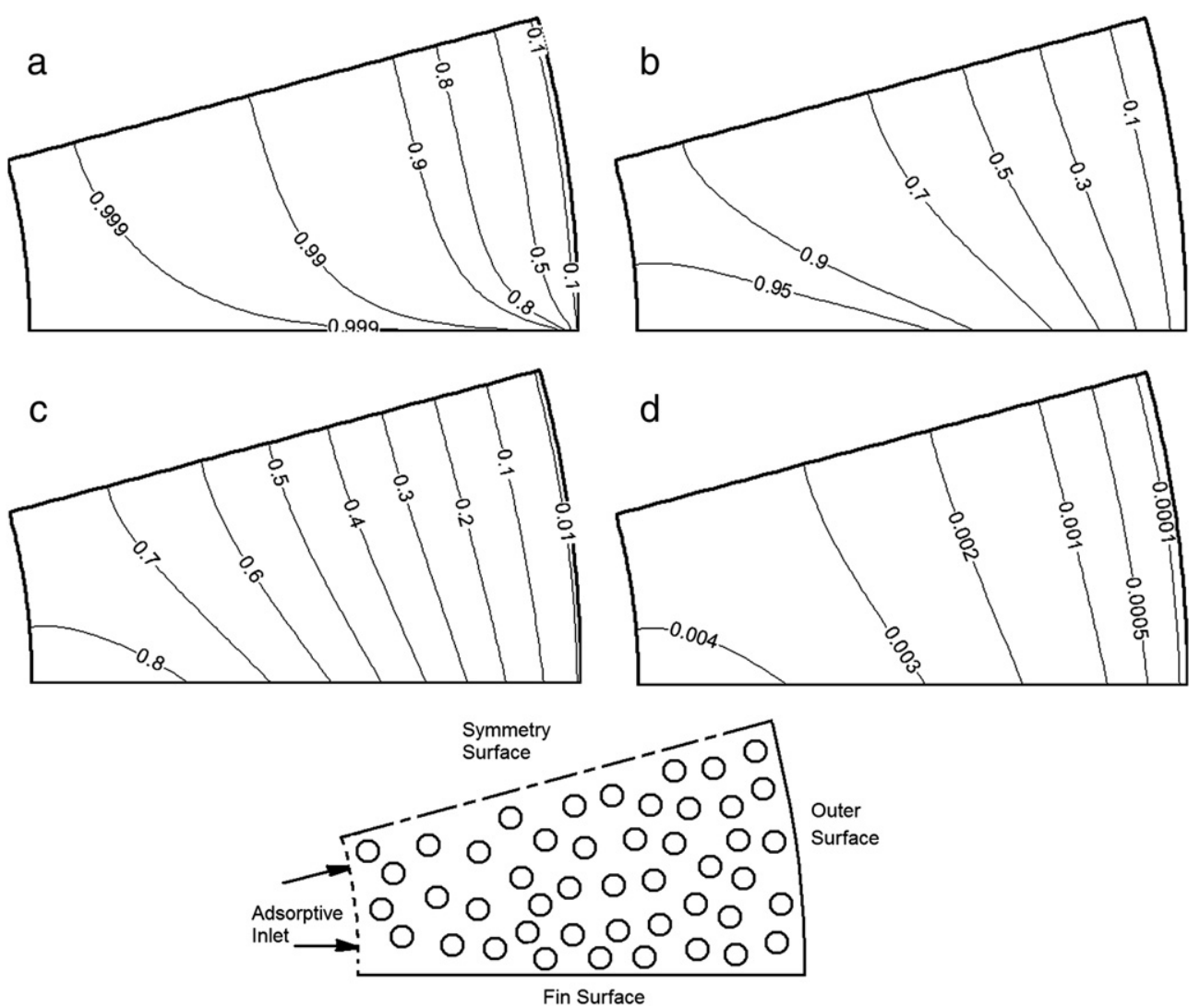

Fig. 6. Dimensionless temperature distribution in the half region between two fins when $\mathrm{Ku}=1, \Gamma=1, \Lambda=0.01$, and $\alpha^{*}=100$, a) $\tau=0.1$, b) $\tau=2$, c) $\tau=10$, and d) $\tau=156.03$. 


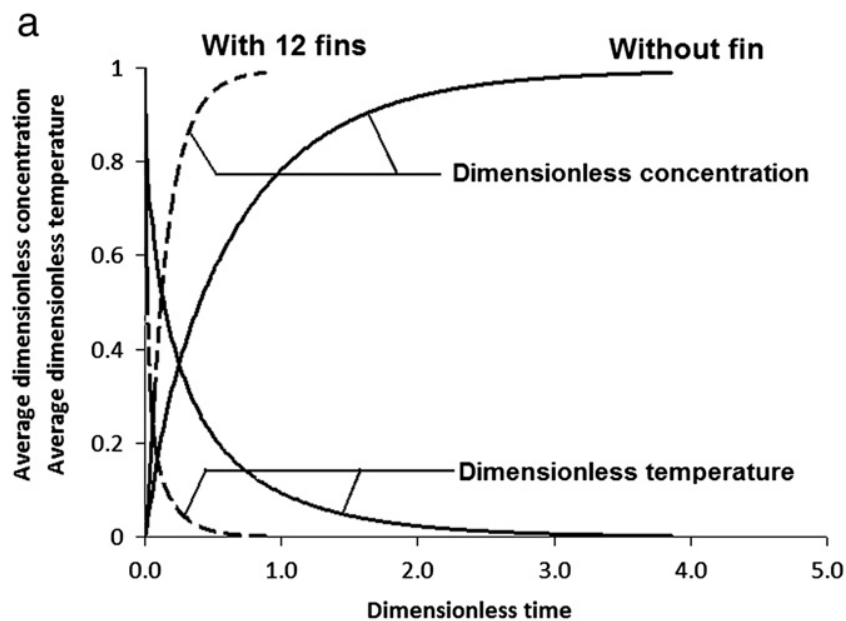

b

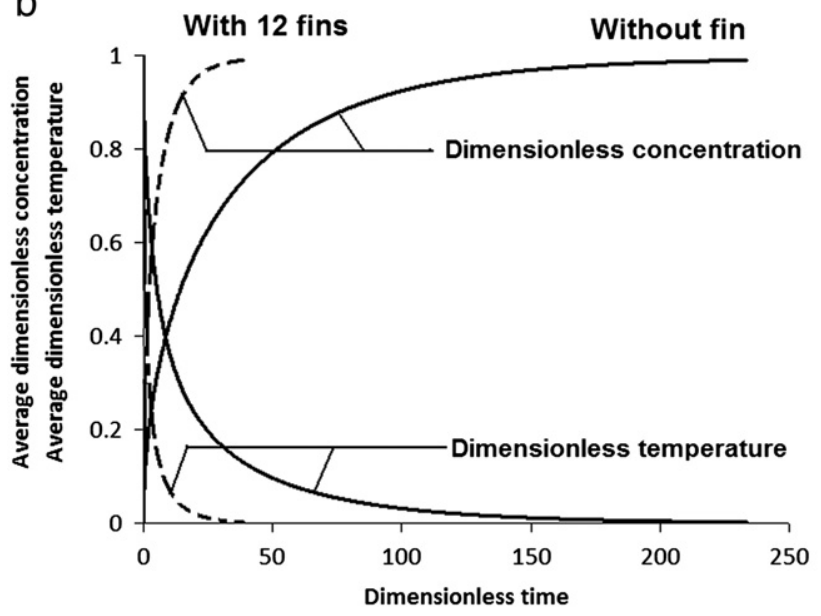

Fig. 7. The changes in dimensionless average temperature and adsorbate concentration with dimensionless time for the adsorbent bed with 12 fins when $\Lambda=0.01$ and $\alpha^{*}=0.01$ and for a bed without fin, a) $\mathrm{Ku}=1$ and $\Gamma=1$, and b) $\mathrm{Ku}=100$ and $\Gamma=1$.

adsorption period. The use of fin does not influence the period of adsorption process since heat transfer in the bed is quicker than mass diffusion in the adsorbent particle, considerably. For an adsorbent bed with a low value of $\Gamma$ (i.e., $\Gamma=10^{-5}$ ), the period of the adsorption

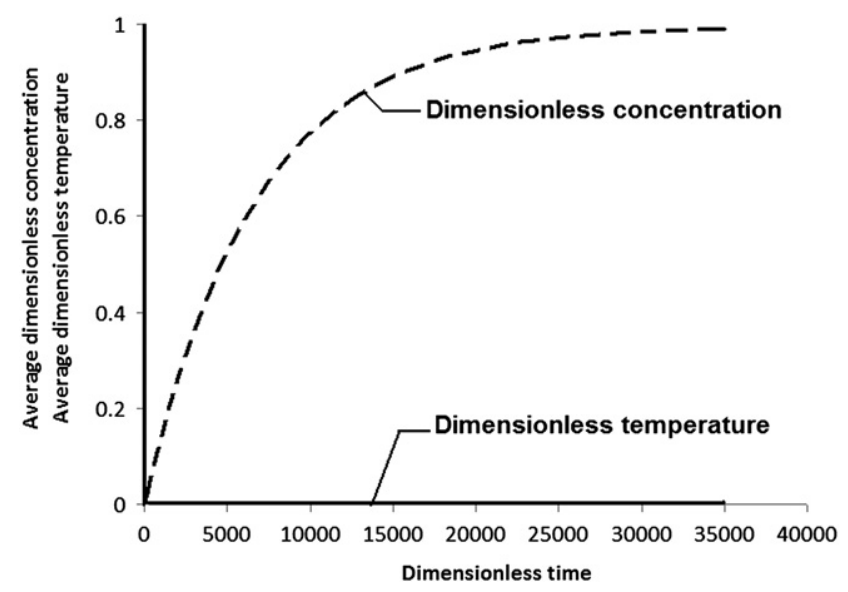

Fig. 8. The variation in dimensionless average temperature and adsorbate concentration with dimensionless time for the adsorbent bed without fin when $\Gamma=10^{-5}$ and $\mathrm{Ku}=1$ and 100

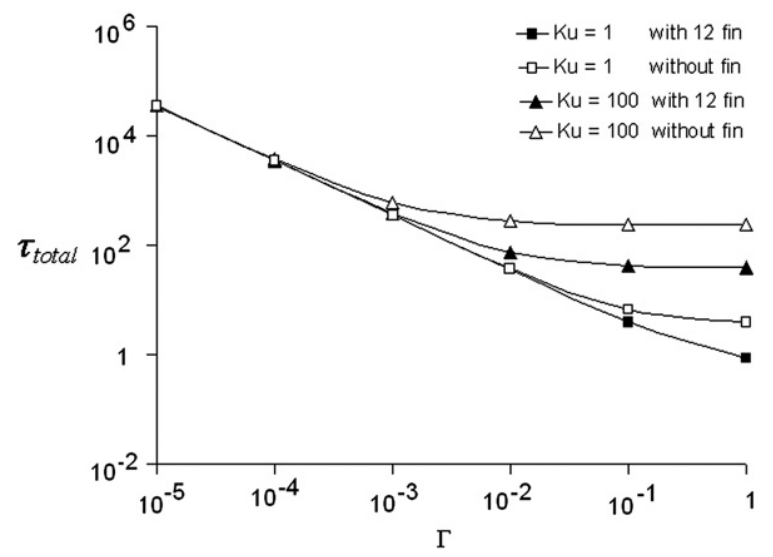

Fig. 9. Variation in dimensionless total period of adsorption process with $\Gamma$ for the adsorbent bed with 12 fins when $\Lambda=0.01$ and $\alpha^{*}=0.01$ and for the same bed without fin.

process can be shortened only by reducing mass transfer resistance in the adsorbent particle. A comparison between Figs. 7(a) and 8 shows that, a decrease in the value of $\Gamma$ from 1 to $10^{-5}$ prolongs the adsorption period and it is increased from 0.878 to 35000 . The increase of Ku from 1 to 100 does not influence the adsorption period.

The change in total adsorption period with $\Gamma$ for an adsorbent bed with $\mathrm{Ku}=1$ and 100 and for the cases with and without fins are shown in Fig. 9. As seen, the total dimensionless adsorption period for the adsorbent beds with low values of $\Gamma$ (i.e. $\Gamma=10^{-5}$ ) are almost identical for both $\mathrm{Ku}=1$ and 100 . For low values of $\Gamma$, the use of fin does not reduce the adsorption period since heat transfer is rapid and mass diffusion in the particle controls the process. An increase in value of $\Gamma$ reduces the adsorption period. The effect of fin on reduction of adsorption period in an adsorbent bed with high values of $\Gamma$ (i.e. $\Gamma=1$ ) can be clearly seen from Fig. 9. The use of fin reduces the adsorption period and this reduction particularly for the bed with $\mathrm{Ku}=100$ is greater than that of bed with $\mathrm{Ku}=1$.

\section{Conclusion}

The effect of fin on heat and mass transfer in an adsorbent bed with silica gel-water pair during an adsorption process is numerically studied. The governing equations, initial and boundary conditions are non-dimensionalized and it yields four dimensionless parameters as Kutateladze number, thermal diffusivity ratio, dimensionless fin coefficient and a dimensionless parameter as $\Gamma$. The increase of Kutateladze number increases heat generation in the adsorbent bed and consequently the adsorption period increases. The decrease of fin coefficient value causes the increase of heat diffusion in the radial direction of fin and consequently heat and mass transfer in the adsorbent bed is enhanced. The decrease of $\alpha^{*}$ signifies an increase in heat transfer in the fin and consequently the duration of adsorption process is reduced. By decreasing of $\Gamma$ value, mass transfer in the adsorbent particle becomes slower than heat transfer in the bed. For a low value of $\Gamma$ such as $10^{-5}$, mass transfer in the adsorbent particle controls the adsorption process. For low value of $\Gamma$, the use of fin in the adsorbent bed is meaningless since heat transfer in the adsorbent bed is highly rapid. The result of present study is valid for an isobaric adsorption process when $\mathrm{P}=2 \mathrm{kPa}$, adsorption temperature between 303 and $363 \mathrm{~K}$, and for silica gel-water pair. Further studies on various adsorbent-adsorbate pairs under different pressure and working temperatures should be performed to observe the effects of the defined dimensionless parameter groups on heat and mass transport in an adsorbent bed. 


\section{References}

[1] S. Ülkü, M. Mobedi, Adsorption in energy storage, in: B. Kilis, S. Kakac (Eds.), Energy Storage System, Kluwer Academic Publisher, 1989, pp. 487-507.

[2] M.N. Golubovic, W.M. Worek, Influence of elevated pressure on sorption in desiccant wheels, Numerical Heat Transfer. Part A 45 (2004) 869-886.

[3] H.S. Al-Sharqawi, N. Lior, Conjugate computation of transient flow and heat and mass transfer between humid air and desiccant plates and channels, Numerical Heat Transfer. Part A 46 (2004) 525-548.

[4] L.A. Sphaier, W.M. Worek, Numerical solution of periodic heat and mass transfer with adsorption in regenerators: analysis and optimization, Numerical Heat Transfer. Part A 53 (2008) 1133-1155.

[5] C.R. Ruivo, J.J. Costa, A.R. Figueiredo, Analysis of simplifying assumptions for the numerical modeling of the heat and mass transfer in a porous desiccant medium, Numerical Heat Transfer. Part A 49 (2006) 851-872.

[6] H. Demir, M. Mobedi, S. Ülkü, Effects of porosity on heat and mass transfer in a granular adsorbent bed, International Communications in Heat and Mass Transfer 36 (2009) 372-377.

[7] G.G. Ilis, M. Mobedi, S. Ülkü, A parametric study on isobaric adsorption process in a closed adsorbent bed, International Communications in Heat and Mass Transfer 37 (2010) 540-547.
[8] K.C. Leong, Y. Liu, System performance of a combined heat and mass recovery adsorption cooling cycle: a parametric study, International Journal of Heat and Mass Transfer 49 (2006) 2703-2710.

[9] G. Cacciola, A. Hajji, G. Maggio, G. Restruccia, Dynamic simulation of a recuperative adsorption heat pump, Energy 18 (1993) 1125-1137.

[10] L. Marletta, G. Maggio, A. Freni, M. Ingrasciotta, G. Restuccia, A non-uniform temperature non-uniform pressure dynamic model of heat and mass transfer in compact adsorbent beds, International Journal of Heat and Mass Transfer 45 (2002) 3321-3330

[11] L.M. Sun, N. Ben Amar, F. Meunier, Numerical study on coupled heat and mass transfers in an adsorber with external fluid heating, Heat Recovery Systems 15 (1995) 19-29.

[12] H.T. Chua, K.C. Ng, W. Wang, C. Yap, X.L. Wang, Transient modeling of a two-bed silica gel-water adsorption chiller, International Journal of Heat and Mass Transfer 47 (2004) 659-669.

[13] A. Fedorov, R. Viskanta, Scale analysis and parametric study of transient heat/mass transfer in the presence of nonporous solid adsorption, Chemical Engineering Communications 171 (1999) 231-257. 